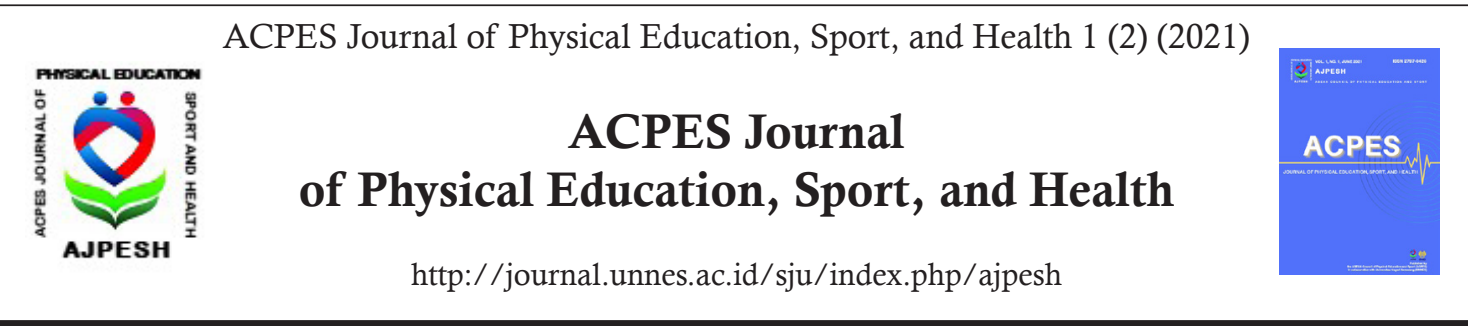

\title{
Investigating the Online Game-based and Group-Based Flipped On- line Learning of Drug Abuse Prevention on Learning Achievement Among Grade 10 Students in Bangkok, Thailand
}

\author{
Sununta Srisiri ${ }^{\bowtie}$, Songmongkorn Mootin \\ Faculty of Physical Education, Srinakharinwirot University, Thailand \\ DOI: https://doi.org/10.15294/ajpesh.v1i2.48083
}

\section{Article Info}

Article History

Submitted 2021-07-09

Revised 2021-09-29

Accepted 2021-11-17

Keywords

Online Game-based learning;

Flipped Classroom Learn-

ing; High School Students

\begin{abstract}
This study was examined the effect of the online Game-based learning versus the Group-Based Flipped Classroom online learning experiences about drug abuse prevention on the learning achievement among grade 10 students in Bangkok, Thailand. Classroom action research was implemented among grade 10 students at high school in Bangkok selected through purposive. Two comparable classrooms were assigned to either the online game-based learning or groupbased flipped online learning for 2 weeks. The instruments employed in the study consisted of: (1) a flipped classroom model with online group investigation, (2) an online game-based model as individual learning, (3) the learning achievement-drug abuse prevention cognitive test. Independent t-test was analyzed to test the effectiveness of the two interventions. It revealed there was a significant difference in the learning achievement of drug abuse prevention given to those who were exposed to online game-based learning and those who were exposed to group-based flipped classroom online learning $(t=3.945, n 1=43, n 2=39, p=0.000)$. From the study, high school students who were exposed to the online game-based learning performed better to those exposed to group-based flipped classroom online learning. Teachers are to encourage students to use individual learning to improve performance.
\end{abstract}

\section{INTRODUCTION}

The COVID-19 pandemic is first and important a health crisis. Many countries have decided to close schools, colleges, and universities. The crisis sets the problem policymakers are facing between closing schools (reducing contact and saving lives) and keeping them open (allowing workers to work and maintaining the economy). The severe short-term disruption is felt by many families around the world: home schooling is not only a massive shock to parents' productivity, but also to children's social life and learning. Teaching is moving online on an untested and unprecedented scale. Student assessments are also moving online, with a lot of trial and error and uncertainty for everyone. Many assessments have simply been cancelled. Essentially, these interruptions will not just be a short-term issue, but can also have long-term consequences for the affected cohorts and are likely to increase inequality. Nevertheless, going to school is the best tool available to raise social skills and social awareness. The key point of being in school is that it increases a child's ability. Even a relatively short time in school does this; even a relatively short period of missed school will have consequences for skill growth. But can we estimate how much the COVID-19 interruption will affect learning? (Burgess \& Sievertsen, 
2020; Kohpaiboon, 2020; Kundu \& Bej, 2021).

There are two evidences are useful. Carlsson et al. (2015) studied the effect of schooling on cognitive skills of young men in Sweden. The sample had differing number of days to prepare for important tests. These differences are conditionally random allowing the authors to estimate a causal effect of schooling on skills. It found that an extra 10 days of school instruction raises cognitive scores on crystallized intelligence tests (synonym and technical comprehension tests) by $1 \%$ of a standard deviation. As an extremely rough measure of the impact of the current school closures, if we were to simply extrapolate those numbers, twelve weeks less schooling (i.e., 60 school days) implies a loss of $6 \%$ of a standard deviation, which is non-trivial. Also, it found that test scores on fluid intelligence tests (spatial and logic tests) do not increase with additional days of schooling.

A different way into this question comes from Lavy (2015), who estimates the impact on learning of differences in instructional time across countries. That is, there are very substantial differences between countries in hours of teaching. The result found that instructional time has a positive and significant effect on test scores, and that the effect is much lower in developing countries. For example, Lavy shows that total weekly hours of instruction in mathematics, language and science is $55 \%$ higher in Denmark than in Austria. These differences matter, causing significant differences in test score outcomes: one more hour per week over the school year in the main subjects' increase test scores by around $6 \%$ of a standard deviation.

Learning experiences can be thought of as how the learning process occurs; specifically, it refers to what goes on while the student is learning and how the student learns what he or she has been taught. The goal of teaching is to ensure that the person being taught is able to understand what he or she is taught and at the end can reproduce or say what he was taught. To achieve this, teachers employ a variety of activities and teaching methods to enhance their teachings to ensure that the students are able to understand and assimilate what they have been taught. These means can either be through group or individual learning. Group learning involves joint intellectual efforts by students and teachers together. Students who engage in group learning usually do this in groups of two or more. They work together to achieve a particular aim. In classrooms of groups, students do more of discussions and class participation (Susan et.al., 2017).

Johnson (2017) noted that a teacher's role and responsibility is to motive students includes, but is not limited to, creating an environment conducive to learning. The teacher's role in encouraging support of students' autonomy, relevance, and relatedness of the material increases motivation to learn. Additionally, the teacher's ability to develop students' competence, interest in subject taught, and perception of self-efficacy are all important factors that influence students' motivation to learn. When a student learns individually, they take all the information they already have and connect it to what they are experiencing now in time to form a new knowledge. This learning can be described as teacher-center. The teacher provides the major source of information, assistance, criticism, and feedback. Yet, traditional lecture-based classroom (LBC) models cannot meet the needs of students and not response the policy of the Thai National Education Ministry what they call "Thailand 4.0" (Royal Thai Embassy Washington D.C., 2015). and thus, a variety of teaching mode reforms have emerged one after another, such as Problem-Based Learning, Case-Based Learning, Team-Based Learning, Flipped classroom (FC), and others (Sanitchai \&Thomas, 2018).

A flipped classroom involves the students reading the lecture material before class and then doing activities related to the lecture material in the classroom (Chua \& Lateef, 2014) This "flips" the time when students are active from their own personal study time to during the traditional lecture time in class. It is a special hybrid teaching (Khanova et al., 2015; Sajid, et.al., 2016). In flipped classroom, students take the initiative to learn before class and solve problems in the process of classroom discussion and cooperation. Different from the traditional passive teaching, flipped classroom is studentcentered participatory learning. Students' complete self-study in their free time. In class, teachers are responsible for guiding students in their communication and answering student questions face-to-face to stimulate student interest in independent learning, promote student participation, and cultivate the students' innovative thinking and scientific research ability (Gonda et al., 2021).

Moreover, studies suggest that students are more likely to remain engaged in an educational activity if technology is involved. Web-based programs, mobile applications and virtual patient simulations are just a few examples of platforms that can incorporate "gamification" (Akl, et.al. 2013; Pettit, McCoy, Kinney \& Schwartz, 2014; Attali, Y. \& Arieli-Attali, M. 2015). On the other word, is a student relying on him or herself for knowledge base. Individual learning implies that knowledge and 
cognitive skill are assets that teachers can transfer to the learner. One example of a gamified learning

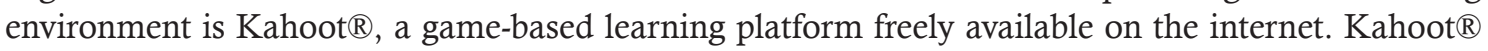
enables professors to create trivia quizzes in any language and on any device. The quizzes can be utilized on any device and in any location that has cell signal or internet. Kahoot ${ }^{\circledR}$ questions can be utilized in a live, class setting in two ways: 1) Questions are projected on a large screen and each student answers the questions on their mobile device. 2) Students view the questions on their own mobile device and submit the answers.

According to the Thailand New National Strategies (2018), learning is both individual and social. Young students are not passive learners as they enjoy participating in 'hands-on' and 'brains-on' activities. They actively drive their own learning and development, by the choices they make, the interests they develop, the questions they ask, the knowledge they seek, and their motivation to act more competently. Working with others to achieve shared meanings and goals can promote many benefits for learners that include learning, social, motivational, and emotional outcomes (O'Donnell, 2006). In classroom settings, collaboration has been used to help students learn concepts in subjects' areas such as mathematics and learn valuable practices such as problem solving. Slavin (1990) also documented the social and emotional outcomes that include building positive relationships among peers, increasing self-esteem, and perspective taking. Collaborating can support young people in learning together with others. Many of these collaborative learning environments, however, typically engage learners in joint problem solving, discussions, brainstorming, or sharing.

Drug abuse has been an important social and public health problem in Thailand for decades. The National Household Survey on Substance and Alcohol Use in Thailand, which has been conducted six times, shows that substance abuse has steadily increased. Extrapolated country-wide in recent data, the estimated number of people who have used at least one addictive substance at some time in their lives was $2,964,444$ or $5.8 \%$ of the total population aged $12-65$ years. Although the Thai government has dedicated human resources and a sizable budget to control drug use, it has become an increasingly severe problem. Many organizations are creating and developing programs, measures, and policies for dealing with substance abuse (Saingam,2018).

In Thailand, young people (10-19 years) are likely to spend more waking hours in the school environment around teachers than at home with their parents, making the school's social environment a key factor influencing the development of young people. Research has shown that a positive relationship with school, which creates a greater sense of community, attachment, and performance, is associated with reduced potential for drug abuse. As a teacher, we can help by correcting common misperceptions that young people have about alcohol and other drugs. One of the most widely held misperceptions is the idea that it is common or normal to use drugs, when in fact most young people have never tried an illegal drug. Young people are trusting of adults and can easily be influenced. Teachers can be role models for students and dissuade them from abusing drugs. It is concluded that strategies for drugs education needed to be developed to fit within each social context (Unicef, 2017). Therefore, a learning model to support high school students who are disposed to be drug users is needed to be developed to fit with high school student in Thailand. A drugs education has been developed with cooperation from students and their teachers which encourage students to learn and practice drug abuse prevention methods, to gain and maintain appropriate attitudes and to develop essential skills about drug abuse prevention.

The objectives of this study are to examine the effect of the online Game-based learning versus the Group-Based Flipped classroom online learning experiences about drug abuse prevention on the learning achievement among grade 10 students in Bangkok, Thailand. Also, this study is designed to determine the kind of learning experience that will enable the high school students to perform better in the online classroom.

\section{METHODS}

This study was based on the classroom action research (CAR) approach using two groups posttest research design. CAR was conducted through a cycle of planning, action, and reflection to identify effective interventions to develop the lesson learn about drug abuse prevention among the participants. CAR is a systematic method to support teacher for finding out what works best in your own classroom so that you can improve student learning. It was developed the teaching and learning activities. (Purrohman, 2011). CAR is one of the most appropriate methods to develop a lesson learn 
suited to a context of the participants.

\section{Setting and Participants}

This study was conducted in a high school in Bangkok, Thailand. The high school students were invited to participate in this study by purposive sampling. The two experiment was conducted in the online learning. Prior to enrollment, eligible students and their parents were informed that they could freely access, participate in or withdrawal from the research at any time. Eighty-two students who were in grade 10 agreed to participate in the study. The students undertook the online game-based learning as individual learning $(n=43)$ and the group-based flipped classroom online learning $(n=39)$ under teachers' and researchers' supervision. Under teachers' supervision, students initiated and conducted activity and engaged in activities for drug abuse prevention throughout 2 weeks, from January 29 to February 5, 2021.

\section{Instrument}

The instruments were (1) a flipped classroom model with online group investigation, (2) an online game-based model as individual learning, (3) the learning achievement-drug abuse prevention cognitive test. There are detail the follows:

(1) the content of drug abuse prevention online lesson plans consisted of 1) information about drug abuse, including information on types of illegal drugs, effects of drug addiction on body, mind, and society, and ways to prevent drug abuse; 2) preventing drug abuse skills; and 3) outline to develop campaign to prevent drug abuse.

(2) a flipped classroom model with online group investigation developed by the researchers - started with lecture videos and other resources shared via Microsoft Team Application before online class. The shift happens when students come to online class, teaming up to work together on that day's assignment. This format encourages students to learn from one another and helps students to not only learn the what the right answers are but also how to explain to a peer why those answers are right.

(3) an online game-based model developed by the researchers-online lecture and electronic games (Kahoot Application) for achieving educational goals.

(4) The drug abuse prevention cognitive tests contained 20 items. The drug abuse prevention cognitive test scoring was marked 1 for correct and 0 for incorrect. The highest score was 20 , and the lowest score was 0 . The reliability was 0.74 .

\section{Research Procedure}

The independent variable in this study was the method of online instruction. This was a variable with two categories - a flipped classroom model with online group investigation and an online game-based learning. The dependent variable was the drug abuse prevention cognitive test score. The test was made up by google form.

After gaining permission from the school principal, the researchers met with high school students to explain the nature of the study and study procedures. On the first day, Informed consent was obtained from the students and from their parents. This interaction lasted about 15 minutes and the students were told about the session for the next day. The researchers communicated with the subject supervisor teacher to determine areas that had been covered and deciding on the topic to be taught. On the experimental period ( 2 weeks), the treatment comprised of two parts: a flipped classroom model with online group investigation, and online game-based model.

A flipped classroom model with online group investigation - initially, the researcher delivered a lecture videos and other resources shared via Microsoft Team Application before class. The shift happens when students come to online class, teaming up to work together on that day's assignment. This format encourages students to learn from one another and helps students to not only learn the what the right answers are but also how to explain to a peer why those answers are right.

An online Game-based learning model - the online lecture and electronic games (Kahoot Application) for achieving educational goals.

After the lesson, all the students were given their question by google form. The first class had the students doing the group work. In this class, we ensured all the students were active. As part of the instructions, students were encouraged to discuss and listen carefully to comments of each member. As experience reveals and with knowledge from group dynamics, group decision making can easily 
be dominated by the student who talks the longest. To mitigate this, every group member was made to contribute his or her ideas. After this, the group arrived at a solution. The students were got the answers to the tests were discussed. The second class had the students that were tested individually, they were well spaced to ensure there was no cheating...

\section{Statistical Analysis}

Frequency and percentage were calculated to describe the general characteristics of high school students. Mean and standard deviations were calculated to determine the addictive substances cognitive test of the students.

The Independent t-test was used to compare statistical differences at $p=0.05$ of mean score of knowledge about addictive substances of the students that were exposed to group online learning and those exposed to individual online learning.

\section{RESULTS AND DISCUSION}

This study was classroom action research (CAR) on two group posttest that examined the effects of online game-based learning and group-based flipped online learning on drug abuse prevention knowledge in high school students. The findings from this study revealed as follows:

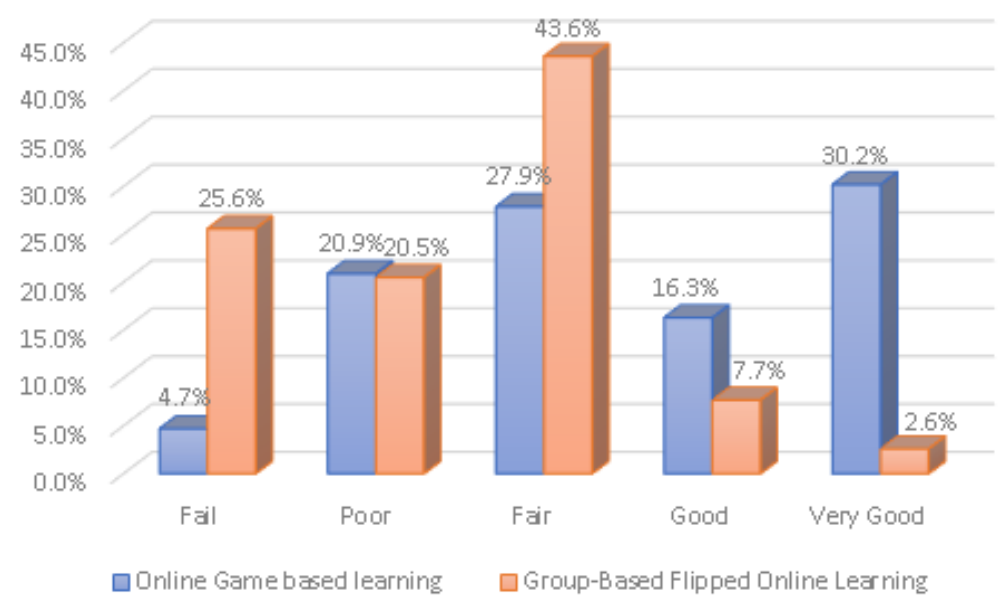

Figure 1. Percentage Posttest score between Online Game-based learning and Group-Based Flipped online learning on drug abuse prevention score of Grade 10 Students in Bangkok, Thailand

In Figure 1, the result showed that the most of grade 10 students who had learned online gamebased learning were very good level (30.2\%), following by fair level (27.9\%), and poor level (20.9\%), respectively. Whereas most of grade 10 students who had learned by group-based Flipped Classroom one learning were Fair level (43.6\%), following by fail level (25.6\%), and poor level (20.9\%), respectively.

Table 2. Comparison Posttest score between Individual and Group online Learning on Addictive Substances Prevention of Grade 10 Students in Bangkok, Thailand

\begin{tabular}{lcccccc}
\hline Interventions & $\mathrm{n}$ & Total score & Mean & S.D. & $\mathrm{t}$ & $\mathrm{p}$-value \\
\hline Online Game-based learning & 43 & 20 & 13.47 & 2.67 & \multirow{2}{*}{$3.945^{*}$} & \multirow{2}{*}{.000} \\
Group-based flipped online learning & 39 & 20 & 11.05 & 2.87 & & \\
\hline
\end{tabular}

In Table 2, the result showed a significant difference in the learning achievement of drug abuse prevention given to those who were exposed to online game-based learning and those who were exposed to group-based flipped classroom online learning $(t=3.945, \mathrm{n} 1=43, \mathrm{n} 2=39, \mathrm{p}=0.000)$. This implied that students who participated in the online game-based learning performed better than those who were exposed to group-based flipped online learning. The mean scores of those who participated 
in the online game-based learning was higher $($ Mean $=13.47)$ than those who were exposed to groupbased flipped online learning (Mean $=11.05)$.

The significance in learning achievement (drug abuse prevention cognitive test) of students exposed to Online game-based learning and Group-based flipped online learning was investigated and the results showed that there was a difference in the performance of the students who were exposed to Online game-based learning and Group-based flipped online learning. From this finding, it was noted that students who participated in the online game-based learning performed better than those who were exposed to group-based flipped online learning. The mean scores of those who participated in the online game-based learning was higher than those who were exposed to group-based flipped online learning since students felt that the additional competition aspect of the drug abuse prevention course added supplementary educational value, thus confirming a there could be practical implications of online game-based learning at the high school level. The students who benefited from gamebased learning showed that Kahoot ${ }^{\circledR}$-mediated teaching sessions strengthened the students' positive attitudes toward online teaching. Our findings are consistent with previous studies that found that Kahoot ${ }^{\circledR}$ incentivized learning and problem-solving skills (Ovanando, Rodriguez \& Hullin, 2018). So, the more prepared the students were for their topic, the more accurately and actively they participated in the Kahoot ${ }^{\circledR}$ discussions. Interestingly, even the less-prepared students were satisfied with how Kahoot $\AA$ advanced their practical capabilities and formed a new interactive, relaxed communication venue between students and supervisors (Felszeghy et.al, 2019). However, our investigation showed that students preferred group-based flipped learning less than to individual gaming since it is hard to join as a group during online face to face via Microsoft Team. Some students in a group-based flipped online class complained that they spend much more time before class (Betihavas et.al.,2016; Lew, 2016; Tang et.al., 2017; Hew \& Lo, 2018; Evans et.al., 2019), have poor absorption and understanding in online class, and what they learn is different from what appears in actual clinical cases (Remington, Hershock \& Klein, 2015; Moraros, Islam \& Yu , 2015).

Furthermore, summary of anonymous responses on the student feedback forms showed that the Kahoot ${ }^{\circledR}$ system was a useful vehicle enabling them to interact with drug abuse content, and that the Kahoot ${ }^{\circledR}$-powered assessment model was an effective approach for asking questions about even difficult aspects of drug abuse. The students also commented concerning to Kahoot i.e. "I really liked Kahoot test because they were a fast and fun way to know if you have studied enough"; "Fun to use and informative because the answer was assessed together"; "Kahoot helped me to learn"; "Sometime Kahoot caused competitiveness and restlessness" etc. However, the students commented concerning to Group-based flipped online learning such as "working and thinking in a good was helpful"; "it was beneficial to discuss or assignments in a small group during the practical classes before getting the correct answers from the teacher".

\section{CONCLUSION}

This study shows that the students preferred online game-based learning activities. As educators, the most concern is to enhance students' learning; therefore, obtaining information about their learning preferences could be one of the ways in achieving this. Teachers should be aware of the learning needs of the students as well as what they want to experience during their classes. This will assist teachers in selecting activities that would cater for the students' learning preferences. Doing this will result in achieving better academic performance as well as other positive learning outcomes. In this study, the online game-based learning provided students with opportunities to analysis synthesize and evaluate ideas. The informal setting facilitated discussion and interaction. In turn, this interaction assisted the students to learn from each other's scholarship, skills, and experiences. The students had to go beyond mere statements of opinion by giving reasons for their judgments and reflecting upon the criteria employed in making these judgments. Thus, each opinion was subject to scrutiny. The ability to admit that one's initial opinion may have been incorrect or partially flawed was valued. According to Bruner (1985), cooperative learning methods improve problem-solving strategies because the students are confronted with different interpretations of the given situation. The peer support system makes it possible for the learner to internalize both external knowledge and critical thinking skills and to convert them into tools for intellectual functioning. Contain conclusions and recommendations. Conclusions contain answers to the research questions. Recommendations refer to the results of research and practical form of action, specify to whom and for what recommendation intended. 


\section{REFERENCES}

Akl, E.A, Sackett, K.M., Erdley, W.S., Mustafa, R.A., Fiander, M., Gabriel, C., et al.2013. Educational Games for Health Professionals. The Cochrane Database of Systematic Reviews.1:CD006411. https://doi.org/10.1002/14651858.cd006411.pub3

Attali, Y. \& Arieli-Attali, M. 2015. Gamification in Assessment: do Points Affect Test Performance?. Computer Education, 83: 57-63. https://doi.org/10.1016/j.compedu.2014.12.012

Betihavas, V., Bridgman, H., Kornhaber, R. \& Cross, M. 2016.The Evidence for 'Flipping Out': a Systematic Review of the Flipped Classroom in Nursing Education. Nurse Education Today, 38: 15-21. https://doi.org/10.1016/j.nedt.2015.12.010

Bruner, J. 1985. Child's Talk: Learning to Use Language. Oxford: Oxford University Press.

Burgess, S. \& Sievertsen, H.H. 2020. Schools, Skills, and Learning: The Impact of COVID-19 on Education. Available at: https://voxeu.org/article/impact-covid-19-education.

Carlsson, M., Dahl, G.B., Öckert, B. \& Rooth, D. 2015. The Effect of Schooling on Cognitive Skills. Review of Economics and Statistics, 97 (3): 533-547. available at: http://www.mitpressjournals. org/doi/pdf/10.1162/REST_a_00501

Chua, S.M.J., \& Lateef, F. 2014. The Flipped Classroom: Viewpoints in Asian Universities. Education in Medicine Journal, 6 (4): e20-e26. DOI:10.5959/eimj.v6i4.316

Evans, L., Bosch, M.L.V, Harrington, S., Schoofs, N. \& Coviak, C. 2019. Flipping the Classroom in Health Care Higher Education: A Systematic Review. Nurse Educator, 44 (2): 74-8. https:// pubmed.ncbi.nlm.nih.gov/30015680/

Felszeghy, S., Pasonen-Seppänen, S., Koskela, A. et al. 2019. Using Online Game-based Platforms to Improve Student Performance and Engagement in Histology Teaching. BMC Medical Education, 19: 273. https://doi.org/10.1186/s12909-019-1701-0.

Gonda, D., Pavlovicova, G., Tirpakova, A. \& Duris, V. 2021. Setting Up a Flipped Classroom Design to Reduce Academic Procrastination. Sustainability, 13 (15): 8668. https://doi.org/10.3390/ su13158668

Hew, K.F. \& Lo, C.K. 2018. Flipped Classroom Improves Student Learning in Health Professions Education: a Meta-analysis. BMC Medical Education, 18 (1): 38. https://doi.org/10.1186/s12909018-1144-z

Johnson, D. 2017. The Role of Teachers in Motivating Students to Learn. BU Journal of Graduate Studies in Education, 9 (1): 46-49. https://eric.ed.gov/?id=EJ1230415

Khanova, J., Roth, M.T., Rodgers, J.E. \& McLaughlin, J.E. 2015. Student Experiences Across Multiple Flipped Courses in a Single Curriculum. Medical Education, 10 (49): 1038-1048. https:// doi.org/10.1111/medu. 12807

Kohpaiboon, A.2020. Industry 4.0 Policies in Thailand. ISEAS Yosof ISHAK Institute. Economics Working Paper. No.2020-02. available at: https://www.iseas.edu.sg/images/pdf/ISEAS_ EWP_2020-2_Archanun.pdf

Kundu, A. \& Bej, T. 2021. Experiencing e-assessment during COVID-19: an analysis of Indian students' perception. Higher Education Evaluation and Development. Vol. ahead-of-print No. aheadof-print. https://doi.org/10.1108/HEED-03-2021-0032

Lavy, V. 2015. Do Differences in Schools' Instruction Time Explain International Achievement Gaps? Evidence from Developed and Developing Countries. Economic Journal, 125 (588): F397-F424. Available at: https://doi.org/10.1111/ecoj.12233

Lew, E.K. 2016. Creating a Contemporary Clerkship Curriculum: The Flipped Classroom Model in Emergency Medicine. International Journal of Emergency Medicine, 9 (1): 25. https://intjem. biomedcentral.com/articles/10.1186/s12245-016-0123-6

Lo, C.K. 2017. Toward a Flipped Classroom Instructional Model for History education: A Call for Research. International Journal of Culture and History, 3 (1): 36-43. Doi: 10.18178/ijch.2017.3.1.075

Moraros, J., Islam, A. \& Yu, S. 2015. Flipping for Success: Evaluating the Effectiveness of a Novel Teaching Approach in a Graduate Level Setting. BMC Med Educ, 15: 27. https://doi. org/10.1186/s12909-015-0317-2

O'Donnell, A.M. 2006. The Role of Peers and Group Learning. In P. A. Alexander \& P. H. Winne (Eds.), Handbook of Educational Psychology (2nd ed., pp. 781-802). Mahway, NJ: Lawrence Erlbaum.

Pettit, R.K., McCoy, L., Kinney, M. \& Schwartz, F.N. 2014. A Multimedia Audience Response Game 
Show for Medical Education. Medical Science Educator. 24:181-7. https://www.academia. edu/18042420/A_Multimedia_Audience_Response_Game_Show_for_Medical_Education

Purrohman, P.S. 2011. Classroom Action Research Alternative Research Activity for Teachers. Research gate. 1-10. https://www.researchgate.net/publication/326083037_Classroom_Action_ Research_Alternative_Research_Activity_for_Teachers

Remington, T.L., Hershock, C. \& Klein, K.C. 2015. Lessons from the Trenches: Implementing Teambased Learning Across Several Courses. Currents in Pharmacy Teaching and Learning, 7 (1): $121-$ 30. http://dx.doi.org/10.1016/j.cptl.2014.09.008

Royal Thai Embassy-Washington D.C. 2015. Thailand 4.0. Available at: http://thaiembdc.org/ thailand-4-0-2/

Sajid, M.R., Laheji, A.F., Abothenain, F., Salam, Y., AlJayar, D. \& Obeidat, A. 2016.Can Blended Learning and the Flipped Classroom Improve Student Learning and Satisfaction in Saudi Arabia? International Journal of Medical Education. 7 (4): 281-285. https://doi.org/10.5116/ ijme.57a7.83d4

Saingam, D. 2018. Substance Abuse Policy in Thailand: Current Challenges and Future Strategies. Journal of Drug and Alcohol Research, 7: 1-10. DOI:10.4303/jdar/236058.

Sanitchai, P. \& Thomas, D. 2018. The Relationship of Active Learning and Academic Achievement among Provincial University Students in Thailand. APHEIT International Journal. 7 (3): 47-61. https://doi.org/10.4236/jss.2019.73017

Slavin. R.E. 1990. Achievement Effects of Ability Grouping in Secondary Schools: A Best-Evidence Synthesis. Review of Education Research, 60 (3): 471-499. Available at: https://doi. org/10.3102/00346543060003471

Ovando, A.S, Rodríguez, A. \& Hullin, C. 2018. Digital Game-Based Learning: A Didactic Experience in the Pre-Degree Nursing Career. Studies in health technology and informatics. 250: 88. https:// pubmed.ncbi.nlm.nih.gov/29857392/

Susan, O.A., Olufunke, O.C., Abiodun, M.G., Olujide, A.A. \& Ebikaboere, O. 2017. Individual and Group Learning on Task Achievement: Impact on Primary School Pupils in Nigeria. Proceedings of ICERI2017 Conference, Seville, Spain, 16th-18th November 2017.

Tang, F., Chen, C., Zhu, Y., Zuo, C., Zhong, Y., Wang, N., Zhou, L, Zou, Y. \& Liang, D. 2017. Comparison between Flipped Classroom and Lecture-based Classroom in Ophthalmology Clerkship. Medical Education Online, 22 (1): 1395679. https://doi.org/10.1080/10872981.2017.139 5679

Unicef. 2017. A Situation Analysis of Adolescents in Thailand 2015-2016. Available at: https://www. unicef.org/thailand/sites/unicef.org.thailand/files/2018-08/adolescent-situation-analysisthailand-en.pdf 